\title{
ZNACZENIE ARCHEOLOGII CHRZEŚCIJAŃSKIEJ DLA INTERPRETACJI PERISTEPHANON PRUDENCJUSZA NA PRZYKLADZIE WYKOPALISK POD BAZYLIKĄ ŚW. PAWŁA ZA MURAMI
}

Kiedy na prośbę ks. prof. Marka Starowieyskiego przygotowywałam tekst o znaczeniu dzieła Prudencjusza dla archeologii chrześcijańskiej ${ }^{1}$, pomyślałam, że warto również sprawdzić, na ile znaleziska archeologiczne mogą być przydatne dla czytelników i badaczy Peristephanon. Spróbuję zatem przedstawić odkrycia dokonane w jednym $\mathrm{z}$ opisanych przez Prudencjusza obiektów, wybierając jako przykład rzymską Bazylikę św. Pawła za Murami².

Wzniesiona z inicjatywy Walentyniana II, Teodozjusza i Arkadiusza, przy drugiej mili Via Ostiensis, wkrótce po roku 384, tzw. Bazylika Trzech Cesarzy stanęła nad grobem Pawła Apostoła, na miejscu starszej i mniejszej budowli, która nie odpowiadała już potrzebom licznie przybywających pielgrzymów ${ }^{3}$. Dedykowano ją w okresie pontyfikatu Syrycjusza $(384-399)^{4}$, ale prace przy dekoracji przeciągnęły się do czasów Honoriusza (395-423) ${ }^{5}$. Ta najwcześniejsza, w historii istniejącej do dziś Bazyliki, faza budowli, zwana „teodozjańską”, dość szybko została poddana przebudowie. Uszkodzenia spowodowane przez trzęsienie ziemi i pożar w 443 roku były na tyle znaczące, że papież Leon

${ }^{1}$ Por. Aureliusz Prudencjusz Klemens, Wieńce męczeńskie, tłum M. Brożek, oprac. M. Starowieyski, ŹMT 40, Warszawa 2006, 100-106 (B. Wronikowska - Znaczenie dzieła Prudencjusza dla archeologii chrześcijańskiej).

${ }^{2}$ Por. Peristephanon XII 45-54, CCL 126, 380, ŻMT 40, 328-329.

3 Por. Epistulae Imperatorum Pontificum aliorum 3, CSEL 35, 46: „Desiderantibus nobis contemplatione venerationis antiquitus iam sacratae basilicam Pauli apostoli pro sanctimonio religionis ornare, pro quantitate conventus amplificare, pro studio devotionis attollere"; zob. V. Saxer, Il culto degli Apostoli Pietro e Paolo dalle origini all'epoca caroliongia, w: A. Donati (red.), Pietro e Paolo. La storia, il culto, la memoria nei primi secoli. Catalogo della mostra (Roma, Palazzo Cancelleria, 30 giugno - 10 dicembre 2000), Milano 2000, 73-85.

${ }^{4}$ Por. ICVR II 4778.

5 Por. ICVR 4780: „THEODOSIUS COEPIT, PERFECIT ONORIUS AULAM/DOCTORIS MUNDI SACRATAM CORPORE PAULI"; zob. M. Fazio, Un discutido testimonio de Prudencio sobre la ornamentación de la basilca ostiense en tiempos de Inocencio I, „Archivum Historiae Pontificiae" 2 (1964) 45-72; tenże, La segunda basilica de San Pablo, extramuros. Estudios sobre su fundación, Roma 1972. 
I (440-461) musiał podjąć prace renowacyjne ${ }^{6}$, które zmieniły nie tylko wystrój wnętrza $^{7}$, ale i sposób eksponowania relikwii Apostoła ${ }^{8}$. Również w następnych stuleciach naturalną koleją rzeczy wygląd budowli podlegał dalszym, aczkolwiek stosunkowo drobnym, zmianom ${ }^{9}$, aż wreszcie pożar, który wybuchł nocą 15/16 lipca 1823 roku, zniszczył ją, pozostawiając zaledwie resztki absydy z łukiem triumfalnym, fragmenty murów (głównie transeptu), oraz ułomki potężnych kolumn ${ }^{10}$. Chcąc więc dotrzeć do stanu z przełomu IV i V wieku, kiedy to Prudencjusz miał możność podziwiania Bazyliki Trzech Cesarzy ${ }^{11}$, uciec się trzeba do wykopalisk.

Okoliczności sprzyjające podjęciu badań archeologicznych pod Bazyliką św. Pawła za Murami pojawiły się w następstwie pożaru. Prace przy usuwaniu jego skutków, a przede wszystkim przy demontażu i odbudowie ołtarza głównego, stały się okazją do pierwszych sondaży. Dokumenty zachowane w archiwum Monasteru św. Pawła, odnalezione i opublikowane dopiero w ostatnich latach $(\mathrm{m}$. in. protokół $\mathrm{z}$ oględzin przeprowadzonych 9 lutego 1838 roku w zagłębieniu pod ołtarzem głównym), pozwalają prześledzić kolejne fazy przeprowadzonych czynności ${ }^{12}$. Dowiadujemy się m. in., że pod Starą Konfesją znaleziono relikwie z inskrypcjami identyfikującymi je jako szczątki Tymoteusza, Juliana, Celsusa, Marcianilli i Bassilli ${ }^{13}$ oraz trzy sarkofagi marmurowe, „con entro corpi ottimamente imbalsamati, ma non si è veduta una lettera sola

${ }^{6}$ Por. Liber Pontificalis, ed. L. Duchesne, I, Paris 1886, 239: „,(basilicam) Pauli post ignem divinum renovavit".

${ }^{7} \mathrm{Z}$ czasów Leona I pochodziła $\mathrm{m}$. in. mozaika na łuku triumfalnym, odtworzona po pożarze z roku 1823 , a być może także najstarsze portrety papieży.

${ }^{8}$ Por. G. Filippi, La Tomba di San Paolo e le fasi della basilica tra IV e VII secolo. Primi risultati di indagini archeologiche e ricerche d'archivio, ,, Bollettino dei monumenti musei e gallerie ponteficie" 24 (2004) 221.

9 Por. N.M. Nicolai (Della Basilica di s. Paulo, Roma 1815, 310) opisując Bazylikę na początku XIX wieku podkreśla jednorodność zarówno jej konstrukcji, jak i dekoracji, zob. M. Cecchelli, Il complesso monumentale della basilica dal IV al VII secolo, w: C. Pietrangeli (red.), San Paolo fuori le mura a Roma, Roma 1988, 37-53; A. Tomei, Vicende della Basilica sino al 1823, w: tamże, s. 55-65.

${ }^{10}$ Te części, które oszczędził pożar, w większości zniszczono podczas prac rekonstrukcyjnych, których celem było przywrócenie Bazylice pierwotnej świetności, por. A.M. Cerioni, L'Incendio del 1823. Problemi e polemiche per la ricostruzione e sua realizzazione, w: tamże, s. 67-83.

${ }^{11}$ Datowanie pobytu Prudencjusza w Rzymie na pierwsze lata V wieku, por. R. Klein, Zur heidnisch-christlichen Auseinandersetzung in Rom um die Wende vom 4. bis zum 5. Jahrhundert: Prudentius in Rom, RQ 98 (2003) 87-111.

${ }^{12}$ Por. G. Filippi, Nuovi documenti sui lavori del 1838 nella Vecchia Confessione, „Bollettino dei monumenti musei e gallerie ponteficie” 25 (2006) 87-95.

13 Relikwie te uroczyście przeniesiono do Camera delle Reliquie della Basilica, aby następnie, zgodnie z wolą papieża Grzegorza XVI, złożyć je pod ołtarzem Nowej Konfesji, por. A. TappiCesarini, Le reliquie conservate nel sacrario della Basilica Ostiense, „Benedictina” 8 (1954) 301-317, spec. 311-312. 
che possa additarci chi Essi fossero"14. Następnie kronikarz informuje o odkryciu jeszcze jednego sarkofagu - marmurowego, z pokrywą zamkniętą ,con grosse grappe di ferro", nienaruszonego i pozostawionego in situ ${ }^{15}$. Obecny podczas dokonywania tych odkryć architekt Virginio Vespignani wykonał szkice ukazujące znalezione obiekty ${ }^{16}$. Z pośpiesznie wykonanych rysunków i notatek domyślać się można, że były to nie tylko sarkofagi (m. in. słynny „sarkofag dogmatyczny”, obecnie przechowywany w watykańskim Museo Pio Cristiano ${ }^{17}$ ), ale i różnego rodzaju (kremacyjne i szkieletowe) groby, a ponadto świadectwa czci, którą w tym miejscu okazywano Pawłowi. Wśród nich znajduje się zwieńczony kratą mur z napisem SALVS POPVLI oraz fragmenty marmurowej płyty z trzema otworami i napisem PAVLO APOSTOLOMART, którą ułożono poziomo pod ołtarzem Nowej Konfesji ${ }^{18}$.

W roku 1850 wykorzystano następną okazję, aby zajrzeć pod posadzkę Bazyliki $^{19}$. Kładąc fundamenty pod ufundowane przez Piusa IX kolumny baldachimu, który miał zwieńczyć cyborium Arnolfa da Cambio, znaleziono $(1,786 \mathrm{~m}$ poniżej ówczesnego poziomu) fragment konstrukcji o kształcie eksedry, zwróconej w kierunku przeciwnym niż Bazylika „teodozjańska”. Zdaniem odkrywcy, Paolo Belloniego, była to absyda, która „,senza dubbio si ritiene esser quella della basilica fondata dall'imperatore Costantino" ${ }^{20}$. Wtedy też, tuż obok, na wysokości skrzyżowania naw z transeptem, odsłonięto fragment drogi, którą identyfikuje się z jedną z dróg wspominanych w tekstach źródłowych (praesens via, bądź iter vetus) $)^{21}$.

${ }^{14}$ Libro delle Memorie della Basilica, cyt. za: Filippi, Nuovi documenti sui lavori del 1838 nella Vecchia Confessione, s. 95.

15 Por. tamże.

${ }^{16}$ Szkice Vespignaniego znajdują się w Biblioteca di Archeologia e Storia dell'Arte w Rzymie, w Collezione Lanciani (mss. 2; 9), por. R. Lanciani, Delle scoperte fatte nel 1838 e 1850 sotto il Sepolcro di Paolo Apostolo, ,Nuovo Bollettino di Archeologia Cristiana” 23 (1917) 7-27.

17 Identyfikacja sarkofagu „Vespignani I” z tzw. sarkofagiem dogmatycznym, por. J. Dresken-Weiland, Sarkophagbestattungen des 4.-6. Jahrhunderts im Westen des Römischen Reiches, Rom - Freiburg - Wien 2003, 144-147, nr kat. E 72.

${ }^{18}$ Jako pierwszy poddał ją badaniom H. Grisar, Die Grabplatte des h. Paulus. Neue Studien über die römischen Apostelgräber, RQ 6 (1892) 119-153.

${ }^{19}$ Zapiski sporządzał wówczas Luigi Moreschi (1802-1886), sekretarz specjalnego zespołu powołanego w $1825 \mathrm{r}$. do spraw związanych z rekonstrukcją Bazyliki, w którego notatniku znajdują się m. in. szkice ukazujące zarys absydy konstantyńskiej oraz informacje na temat dziś już niedostępnych, na skutek podniesienia się poziomu wód gruntowych, pozostałości położonego pod ołtarzem głównym cmentarza ( $m$. in. kolumbarium). Te dotychczas nie opublikowane informacje wykorzystał w swoich badaniach Giorgio Filippi (La Tomba di San Paolo, s. 198, 204-205).

${ }^{20} \mathrm{P}$. Belloni, Sulla grandezza e disposizione della primitiva basilica ostiense stabilita dalla sua absida rinvenuta nell'anno 1850, Roma 1853, 7. Wedug H. Brandenburga (Le prime chiese di Roma IV-VII secolo. L'inizio dell'architettura ecclesiastica occidentale, Milano 2004, 103) była to sala o wymiarach $21 \times 12 \mathrm{~m}, \mathrm{z}$ absydą o średnicy ok. 7,5 m.

${ }^{21}$ Por. P. Liverani, S. Paolo fuori le mura e l'iter vetus, „Bollettino dei monumenti musei e gallerie ponteficie" 9 (1989) 79-84. 
Znaleziska z 1. poł. XIX wieku nie były już później dostępne dla badaczy częściowo uległy zniszczeniu, częściowo zostały zasłonięte Nową Konfesją. Badacze musieli zadowolić się tym, co zachowało się w opisach i rysunkach sprzed pożaru ${ }^{22}$ oraz tym, co udało im się zrozumieć ze sporządzonych na prywatny użytek zapisków Vespignaniego ${ }^{23}$.

Warunki odpowiednie dla prac archeologicznych pojawiły się znów dopiero na początku XXI wieku. Rezultaty wykopalisk, przeprowadzonych w okresie od 17 czerwca 2002 r. do 22 września 2006 r. pod kierunkiem Giorgio Filippiego, okazały się prawdziwą rewelacją ${ }^{24}$. Zdaniem archeologów, którzy ponownie poddali analizie miejsce pod ołtarzem głównym i pod sąsiadującym z nim ołtarzem św. Tymoteusza, nie ulega wątpliwości, że marmurowy sarkofag (dług. 2,55 m, szer. 1,25, wys. 0,97) odkryty w 1838 roku pod ołtarzem Konfesji i nadal pozostający in situ jest miejscem, w którym złożono szczątki św. Pawła. Sarkofag stoi bezpośrednio pod płytą z napisem PAVLO APOSTOLOMART, przy czym jeden $z$ otworów tej płyty znajduje się nad analogicznym otworem wywierconym w pokrywie sarkofagu ${ }^{25}$. Kontekst, w jakim sarkofag przetrwał od umieszczenia go w końcu IV wieku wewnątrz łuku absydy „konstantyńskiej”, a zarazem w centralnym punkcie Bazyliki „teodozjańskiej” świadczy o tym, że kiedy konsekrowano bazylikę, wiernym całego świata wskazano ten sarkofag jako grób świętego Pawła.

Badania warstw archeologicznych pozwoliły na wyciągnięcie następujących wniosków: aby tłumom wiernych, którzy przybywali w końcu IV wieku do grobu Apostoła, umożliwić bliski kontakt z jego relikwiami, wydobyto je z pierwotnego grobu, który zresztą musiał być wówczas coraz bardziej zagrożony przez wody gruntowe, złożono w sarkofagu i wyeksponowano ustawiając na osi budowli, na podwyższeniu ${ }^{26}$, pod łukiem triumfalnym, który - wsparty

22 Najcenniejszym wśród nich źródłem informacji jest do dziś publikacja N.M. Nicolai, Della Basilica di S. Paolo, Roma 1815 (z doskonałymi planami A. Alippiego).

23 Por. Zob. G. Belvederi, L'origine della Basilica Ostiense, RivAC 22 (1946) 103-138; E. Kirschbaum, Die Gräber der Apostelfursten: St. Peter und Paul in Rom, Leipzig 1974, 170-201; R. Krautheimer - S. Corbet - A.K. Frazer, Corpus Basilicarum Christianarum Romae, V, Città del Vaticano 1977, 93-164; F. Tolotti, Le confessioni succedutesi sul sepolcro di S. Paolo, RivAC 59 (1983) 87-149; C. Barucci, Virginio Vespignani, architetto tra Stato Pontificio e Regno d'Italia, Roma 2006, 162-164.

${ }^{24}$ Por. Filippi, La Tomba di San Paolo, s. 187-224; tenże, Die Ergebnisse der neuen Ausgrabungen am Grab des Apostels Paulus. Reliquienkult und Eucharistie im Presbyterium der Paulsbasilika, ,Mitteilungen des Deutschen Archäologischen Instituts. Römische Abteilung” 112 (2005/ 2006) 277-292.

25 Płyta ta licowała prawdopodobnie wówczas jedną z bocznych ścian sarkofagu. Pozostałe ściany były prawdopodobnie licowane podobnymi płytami, na których mogła się znajdować brakująca część inskrypcji, być może dedykacyjnej, por. H. Brandenburg, Die Architektur der Basilika San Paolo fuori le mura. Das Apostelgrab als Zentrum der Liturgie und des Märtyrerkultes, „Mitteilungen des Deutschen Archäologischen Instituts. Römische Abteilung" 112 (2005/2006) 248.

${ }^{26}$ Badania warstw archeologicznych wykazały, że w końcu IV wieku poziom posadzki transeptu był wyższy o $0,54 \mathrm{~m}$ od poziomu nawy. Podniesiono go jeszcze bardziej w okresie pontyfikatu 
na potężnych jońskich kolumnach (wys. $13 \mathrm{~m}$ ) - monumentalizował i uświetniał to miejsce ${ }^{27}$, być może wyróżnione dodatkowo wieńczącym je baldachimem ${ }^{28}$. Relikwie były tym samym nie tylko łatwo dostępne dla czcicieli męczennika, ale także, co stanowiło nowość w architekturze chrześcijańskiej, znalazły się w centrum czynności związanych z liturgią eucharystyczną ${ }^{29}$. Aczkolwiek nie znaleziono jednoznacznych śladów, które umożliwiłyby lokalizację ołtarza, badacze zgadzają się, że w Bazylice Trzech Cesarzy związek między sarkofagiem a miejscem sprawowania Eucharystii był bardzo bliski ${ }^{30}$.

Dzięki wynikom sondaży przeprowadzonych w 1999 roku w różnych miejscach obecnej budowli ${ }^{31}$ oraz późniejszym intensywnym badaniom, uzupełniającym i weryfikującym dokumentację sprzed pożaru ${ }^{32}$, obraz Bazyliki „teodozjańskiej”, która - wedle słów Prudencjusza - „Pawła strzeże grobu”33, wydaje się dość klarowny. Z pewnością była to monumentalna (128 x $65 \mathrm{~m})$ bazylika, z transeptem i absydą. Korpus budowli prawdopodobnie poprzedzało atrium (o długości $66 \mathrm{~m})^{34}$, z którego wejście prowadziło do wnętrza podzielonego na pięć naw (długość naw 90 m; szerokość nawy głównej 24 m; wysokość: nawy głównej $30 \mathrm{~m}$; naw bocznych wewnętrznych $16 \mathrm{~m}$, zewnętrznych $11 \mathrm{~m}$ ). Nawy rozdzielało 80 połączonych arkadami kolumn (o wysokości 10,40 m w nawie głównej i $8,50 \mathrm{~m} \mathrm{w}$ bocznych).

Częściowo zachowane kolumny Bazyliki św. Pawła, które były przedmiotem podziwu nie tylko Prudencjusza, ale i przedstawicieli wielu następnych pokoleń pielgrzymów i badaczy ${ }^{35}$, znajdują się w zbiorach muzeum przy Klasz-

Leona Wielkiego, a następnie Grzegorza Wielkiego i sarkofag został częściowo, a potem całkowicie zasłonięty.

${ }^{27}$ Por. Brandenburg, Die Architektur der Basilika San Paolo fuori le mura, s. 252-264.

28 Por. tamże, przyp. 86.

29 Por. tamże, s. 237-292.

${ }^{30}$ Por. Hieronymus, Contra Vigilantium 8. Giorgio Filippi (Die Ergebnisse, s. 282-284) jest zdania, że sarkofag pełnił wręcz funkcję ołtarza. Hugo Brandenburg (Die Architektur der Basilika San Paolo fuori le mura, s. 270) wyklucza jednak taką możliwość.

31 W latach 1959 i 1971, przy okazji prac budowlanych, widziano jakieś obiekty pod posadzką transeptu i prawej nawy bocznej, ale nie sporządzono żadnej dokumentacji. W 1999 roku poddano te miejsca uważniejszym obserwacjom, których wyniki ogłoszono. Odnaleziono wówczas m in. na głębokości 1,19 m, niewielkie fragmenty marmurowej posadzki „teodozjańskiej”, por. G. Filippi, Ricerche in corso sulla Basilica di S. Paolo f. l. m., , Rendiconti della Pontificia Accademia Romana di Archeologia" 72 (1999-2000) s. XXI; G. Filippi - S. De Blaauw, San Paolo fuori le mura: la disposizione liturgica fino a Gregorio Magno, ,Mededelingen van het Nederlands Instituut te Rome" 59 (2000) 5-25.

32 Por. M. Docci, San Paolo fuori le mura. Dalle origini alla basilica delle origini, Roma 2006.

33 Peristephanon XII 45, CCL 126, 380, ŹMT 40, 328.

${ }^{34}$ Por. J.Ch. Picard, Le quadriportique de Saint Paul hors les murs à Rome, „Mélanges de l'Ecole Française de Rome. Antiquité" 87 (1975) 377-395.

${ }^{35}$ Por. m.in. F.W. Deichmann - A. Tschira, Die frühchristlichen Basen und Kapitelle von S. Paolo fuori le mura, ,Mitteilungen des Deutschen Archäologischen Instituts. Römische Abteilung" 54 (1939) 99-111. 
torze i Bazylice (Parco di S. Paolo). Hugo Brandenburg poddał je drobiazgowym obserwacjom, które wykazały, że kolumny zwieńczone kapitelami korynckimi i kompozytowymi, wykonano specjalnie dla Bazyliki przez kamieniarzy z warsztatów cesarskich, z lśniąco białego marmuru prokonezyjskiego ${ }^{36}$. Nie był to zatem, jak pisał Prudencjusz, marmur paryjski, ale i tak jego jakość i jednolity wygląd kolumn musiały wywierać wrażenie na ludziach epoki późnego antyku, przyzwyczajonych do stosowania materiałów z rozbiórki nawet w najbardziej prestiżowych budowlach. Trzy stopnie prowadziły do transeptu (długość $71 \mathrm{~m}$, wysokość $26 \mathrm{~m}$ ), wyniesionego od początku, jak wykazały ostatnio przeprowadzone badania archeologiczne, ponad pół metra nad poziom nawy ${ }^{37}$. Otwarta w transepcie absyda (wysokość $23 \mathrm{~m}$ ), oddzielona od naw łukiem triumfalnym, była takiej samej szerokości jak nawa główna (24 m).

Badania konstrukcji dachowej, przeprowadzone w ramach projektu realizowanego pod kierunkiem Hugo Brandenburga, pozwoliły stwierdzić, że nad nawą główną rozpościerała się otwarta więźba dachowa, której elementy były, jak pisze Prudencjusz, polichromowane i złocone ${ }^{38}$.

Niewiele można powiedzieć natomiast o dekoracjach ścian Bazyliki, które podziwiał Prudencjusz, ponieważ już w połowie $\mathrm{V}$ wieku zastąpiły je malowidła i mozaiki wykonane na polecenie Leona Wielkiego. Ostatnie odkrycia pozwalają jednak na wysunięcie hipotezy datującej na okres teodozjański przynajmniej jeden z obrazów w nawie głównej. Zdaniem Herberta L. Kesslera, przedstawienie ukazujące spotkanie Piotra i Pawła (tzw. Concordia Petri et Pauli), doskonale wpisuje się w klimat batalii, którą w tamtej epoce prowadzono, aby przywrócić Pawłowi pozycję równą z pozycją Piotra ${ }^{39}$. Znacznie bardziej ryzykowne wydają się podejmowane przez różnych autorów próby rekonstruowania innych elementów dekoracji, która ulegała licznym zmianom w długiej historii Bazyliki ${ }^{40}$.

Pamiętając o zasadzie, która autorom tekstów przeznaczonych do Festschriftu nie pozwala zajmować zbyt wiele miejsca, przerwać muszę relacjonowanie odkryć, które w ostatnich latach tak znacząco wzbogaciły naszą wiedzę

${ }^{36}$ Por. H. Brandenburg, Die Basilica S. Paolo fuori le Mura, der Apostel-Hymnus des Prudentius (Peristeph. XII) und die architektonische Ausstattung des Baues, w: F. Guidobaldi A. Guiglia Guidobaldi (red.), Ecclesiae Urbis. Atti del Congresso internazionale di studi sulle chiese di Roma IV-X secolo (Roma, 4-10 settembre 2000), II, Città del Vaticano 2002, 1526-1578; tenże, Beobachtungen zur architektonischen Ausstattung der Basilika von S. Paolo fuori le mura in Rom, w: Alvarium. Festschrift für Christian Gnilka, hrsg. R. Henke u.a., Münster 2002, 82-107.

${ }^{37}$ Por. Filippi - De Blaauw, San Paolo fuori le mura, s. 5-25.

38 Por. Brandenburg, Die Basilica S. Paolo fuori le Mura, s. 1532-1540.

39 Por. H.L. Kessler, Seroux's Decadent Column Capital and other Pieces in the Puzzle of S. Paolo fuori le mura in Rome, „Arte Medievale NS” 3 (2004) 19-34; zob. B. IwaszkiewiczWronikowska, Najstarsze przedstawienia Piotra Apostoła a problem prymatu papieskiego, VoxP 24 (2004), t. 46-47, 391-404.

${ }^{40}$ Por. Kessler, Seroux's Decadent, s. 9-34. 
o Bazylice św. Pawła za murami. Czy informacje zdobyte przez archeologów okażą się przydatne dla badaczy dzieł Prudencjusza? O tym zdecydują oni sami.

\section{ARCHEOLOGIA CHRISTIANA IN INTERPRETATIONE AURELII PRUDENTII „PERISTEPHANON” XII 45-54 DE S. PAULI SEPULCRO AC BASILICA ROMANA}

$$
\text { (Argumentum) }
$$

Hac in dissertatiuncula recentes excavationes archeologicae sub Romana Basilica S. Pauli extra muras, de qua iam IV saecolo Aurelius Prudentius in Peristephanon XII 45-54 scripsit, recensentur. 